\section{The two sides of the spectrum: Paravalvular mitral regurgitation}

A 63-year-old patient was admitted to undergo transesophageal echocardiography (TEE) to exclude left atrial appendage (LAA) thrombus prior to pulmonary vein isolation. He had a history of prosthetic mitral valve replacement. Although there was no thrombus, three-dimensional imaging of the mitral replacement valve revealed a tiny dehiscence at the 9-o'clock position adjacent to the LAA ostium (Fig. 1a; Video 1) and trivial paravalvular regurgitation at this point (Fig. 1b; Video 2). The patient has been followed without any further intervention or medication.

A 33-year-old patient was admitted to the intensive care unit because of dyspnea at rest. She had a history of recent mitral annuloplasty due to mitral regurgitation. Although severe eccentric mitral regurgitant jet was observed on transthoracic echocardiography, the exact nature of regurgitation and valvular anatomy were not fully elucidated. Therefore, three-dimensional TEE was performed, and it revealed a huge dehiscence between the annuloplasty ring and mitral annulus (Fig. 2a; Video 3). Severe paravalvular mitral regurgitation by color Doppler imaging and teared and wavering posterior mitral leaflet tissue were also observed (Fig. $2 \mathrm{~b}$; Video 4). After prosthetic mitral valve replacement, the patient was discharged without any complications.

Paravalvular regurgitation may occur as a result of disruption of surgical sutures precipitated by infectious endocarditis, significant calcification, or friable tissue at the suturing site. Despite a common finding, their clinical and hemodynamic significance can be highly variable, ranging from asymptomatic patients to the development of heart failure. Three-dimensional imaging can pro-
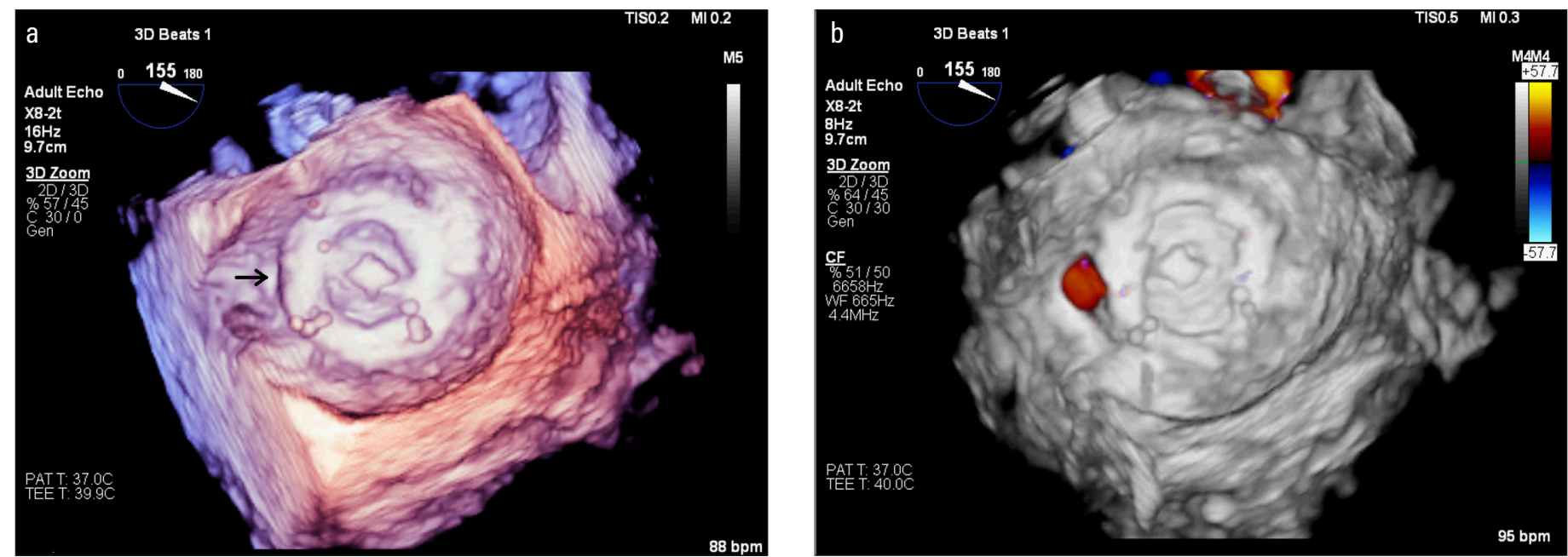

Figure 1. Three-dimensional transesophageal echocardiographic appearance of prosthetic mitral valve replacement from the surgical view. The black arrow indicates a tiny dehiscence at the 9-o'clock position (a), and color Doppler imaging shows trivial paravalvular regurgitation (b)
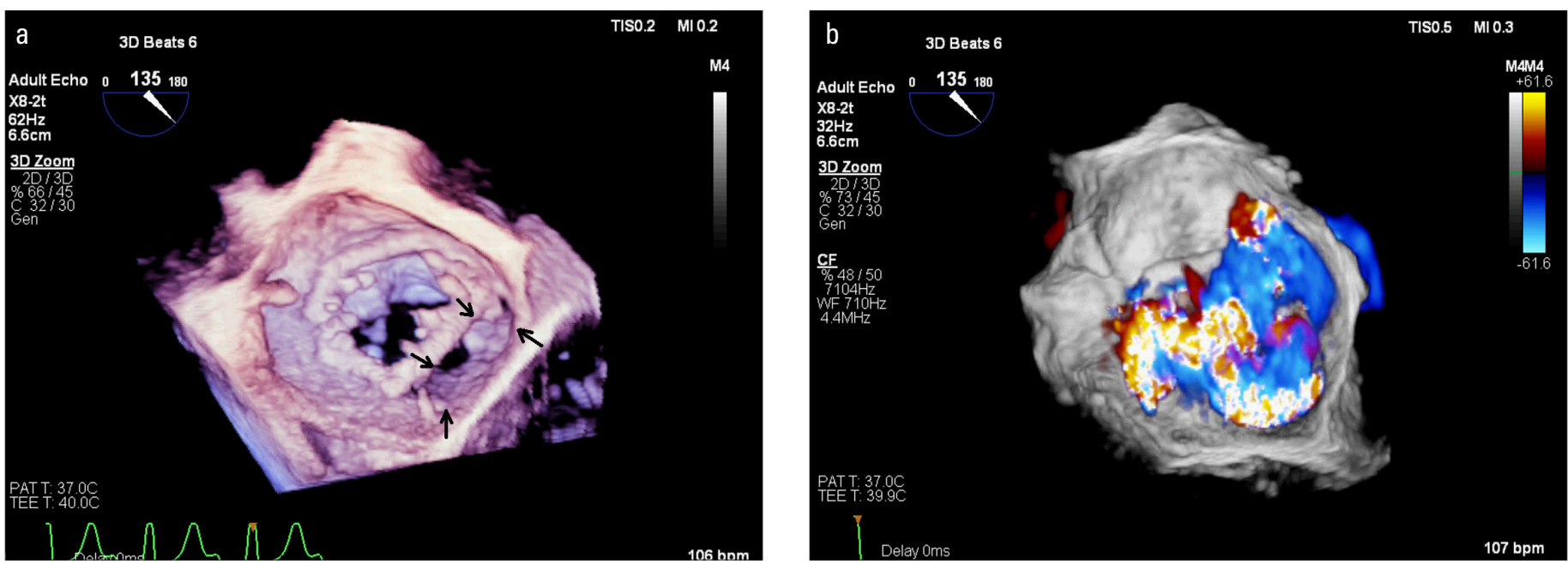

Figure 2. Three-dimensional transesophageal echocardiographic appearance of the mitral annuloplasty ring from the surgical view. Black arrows indicate a huge dehiscence between the 3-o'clock position and 6-o'clock position (a), and color Doppler imaging shows severe paravalvular regurgitation (b) 
vide more accurate structural and functional information in these patients.

Informed consent: Written informed consent was obtained from the patients.

Video 1. Three-dimensional image of prosthetic mitral valve replacement and a small dehiscence adjacent to the left atrial appendage ostium

Video 2. Three-dimensional color Doppler image of the prosthetic mitral valve replacement and a trivial paravalvular regurgitation through small dehiscence adjacent to the left atrial appendage ostium

Video 3. The three-dimensional image shows a huge dehiscence between the annuloplasty ring and mitral annulus between the 3-o'clock position and 6-o'clock position and accompanying teared and wavering posterior mitral leaflet

Video 4. The three-dimensional color Doppler image shows the mitral annuloplasty ring and severe paravalvular mitral regurgitation through this dehiscence

\section{Uğur Nadir Karakulak (D), Necla Özer (1) \\ Department of Cardiology, Faculty of Medicine, Hacettepe University; Ankara-Turkey}

Address for Correspondence: Dr. Uğur Nadir Karakulak, Hacettepe Üniversitesi Tıp Fakültesi, Kardiyoloji Anabilim Dalı, Sıhhiye 06170, Ankara-Türkiye Phone: +90 3123051780

E-mail: ukarakulak@gmail.com

CCopyright 2021 by Turkish Society of Cardiology -

Available online at www.anatoljcardiol.com

DOI:10.5152/AnatolJCardiol.2021.77756 